\title{
Does More And Better Information Enhance Student Performance On Marketing Projects?
}

Lynn F. Muller, (E-mail: Imuller@usd.edu), University of South Dakota

Chip E. Miller, Drake University

James Reardon, University of Northern Colorado

\begin{abstract}
There is some controversy over the amount of guidance students need to complete course projects. One school of thought argues that students should have maximum information at their disposal, resulting in a better learning process and thus a better project. The other school of thought suggests that by giving the students too much guidance, the professor is stifling their creativity and original thought. This research examines both scenarios. The results indicate that minimum information provided by the professor encourages students to learn more. However, should the professor decide to provide the students with additional information, such information should be developed by the professor.
\end{abstract}

\section{INTRODUCTION}

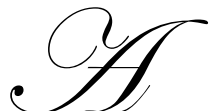

survey conducted by the National Commission on Writing $(2003,2004)$ summarized the concerns of Corporate America regarding written communications. Corporate CEO's and leadership rated accuracy, clarity, conventions, and conciseness as extremely important to effective communication. Survey respondents strongly supported the focus and conclusions of the Commission's 2003 report that stated in part "Writing is not simply a way for students to demonstrate what they know. It is a way to help them understand what they know." (Florida Department of Education, 2005). Therefore, it is reasonable and desirable that graduates of business schools possess and can demonstrate effective writing skills. Student projects have been one method of providing the opportunity to develop and hone these skills.

How then can a professor improve the quality of student projects in marketing? Experience in the classroom has shown that marketing projects can be overwhelming to students when they are confronted with the large number of variables that must be dealt with. Often their performance on group projects is less than desired due to the plethora of variables to deal with, as well as free rider problems (McCorkle, Reardon et al., 1999). The students are unfamiliar with the data sources or sometimes do not take advantage of ones that are available.

Also, there is the ongoing problem of uncertainty of the professor's expectations concerning depth of coverage and writing standards. Nelson and Hayes (1988) found significant differences in college freshman and more advanced upperclassman and graduate students in how they planned and searched for information. Students who used a content driven approach were very concerned with "How easily the information could be extracted" (Nelson and Hays, 1988). Students limited their research to only a few sources, basing their choices on " $\ldots$ how much the books contents overlapped, overlapping content being interpreted as a sign of agreement among authors and hence correctness" ( Nelson and Hayes, 1988, p.5). One of their research subjects reported that if the material in a source is spread out over several places in the text then the book should be rejected because you would have to read too much. She further explained that students should try and find sources that have "pockets or chunks of information that can be easily read and summarized" (Nelson and Hayes, 1988). 
Fortunately, the case for having students conduct group projects has been well established. Henke et al. (1988) state that such projects bring reality to the classroom, enhance students' grasp of an industry and may provide career advancement. Projects force the student to become actively involved in studying the elements that affect both the marketplace as well as the workplace. Roach, Johnston and Hair (1993) echo these thoughts and add that projects improve both written and oral communication skills. Finally, students themselves realize the value of such projects, especially when the projects allow them to apply concepts recently learned to real situations (Karns, 1993).

The problem arises, however, when the professor attempts to gain the most pedagogical value possible from the project. Batra and Walvoord (1997) provide a very detailed outline of tools used to enhance the quality and value of marketing projects. It was judged by students to be very valuable, but appears quite labor intensive. On a more general level, Gaidis and Craig (1990) note four analytical difficulties that students universally experience when producing a project. These are 1) reporting not evaluating, 2) general recommendations rather than specifics, 3) not using hard information and 4) a piecemeal approach that does not demonstrate a cohesive flow from one topic to another.

\section{HYPOTHESIS DEVELOPMENT}

Supplying students with more information should enable them to better determine precisely what areas need to be covered in their report. However, if only told to "follow the text", they may either become overwhelmed by the quantity of information they must sort through, or their lack of experience and desire for ease in completing the assignment may not permit them to select what is most important to emphasize. The result is often that the student wanders off on tangents of personal interest that have no bearing on the paper, or more frequently, that they gloss over critical points without providing any analysis or justification for their answers. Thus:

H1: As student information availability increases, so too will students' performance on the project.

Alternatively, the second school of thought suggests having additional information available to the students in the form of exemplar papers will stifle creativity and thought, essentially allowing the students to "adapt" information rather than creating an output based on thought. Students are inherently efficient and will take whatever shortcuts are made available. Giving them a detailed template to follow will lead them to merely check off each topic as they go, assuming that having it in their paper means they have covered the subject adequately. As one study found in examining students attitudes towards research papers, a common response was that teachers wanted to test the ability of students to trace down and dig up information, and to put that information into a "reasoned" paper (Schweglar and Shamoon 1982). Similarly, using exemplar papers may not present certain aspects of the project that are unique to the student's choice of product. For example, if you chose an industrial good for the exemplar paper, packaging would be a trivial section in the paper. Were the student to select an impulse good, such as a new soft drink or candy, packaging would be critical to success and perhaps not covered with as much depth as necessary.

Students also may tend to follow the path of least resistance and choose products that are similar to those of the examples. Projects on beer and soft drinks tend to proliferate, while those on more unusual products such as Viagra or Caterpillar's marine products division are ignored. Therefore:

H1a: As student information availability increases, students' performance on the project will decline.

The second hypothesis revolves around the completeness of the information available to students. We suggest that not only does the quantity of information affect students' performance, but also the quality of such information. Lack of experience may contribute to students' inability to write as well as desired. Also, differing standards both between students and professors, and among professors, may result in student submissions that are inadequate for a particular class. Demonstrating clearly the quality required should eliminate confusion on the part of the student about what is expected. Hence:

H2: As student information quality increases, so too will students' performance on the project. 


\section{METHODOLOGY}

In order to examine the effect of information availability and quality on student performance, we designed two different levels of information availability and two levels of information quality. Information availability was addressed by providing students with either a detailed outline of the project or example projects and the detailed outline. Information quality was manipulated at the exemplar project level by giving some groups previously completed student projects or giving the students a project (exemplar) completed by the professor.

\section{The Project Outline}

The initial task was to set up the overall guidelines for the group project, which was accomplished in the following manner. The project was described in great detail in the course syllabus (See outline attached in Appendix A).

The outline provided the explicit guidelines as to what specific topics under each heading needed to be addressed by the students, and whether or not quantitative analysis was expected. For example, instead of just asking for three environmental trends that might affect their selected business, the students were tasked with finding three that directly affected, in a significant fashion, their particular product. Then, to ensure that they understood the ramifications of their discovery, they were asked to explain what marketing actions they as product managers needed to take in order to exploit or nullify the outcomes of the trends.

Initially, two sections of a Marketing management class were given the outline only. The resultant papers/projects served as a pool from which student examples/exemplars were selected.

\section{Information Availability}

Information Availability was manipulated as follows. Student projects from the first two sections of Marketing Management mentioned above were chosen based on superior writing skills, depth of coverage of the desired topics, and in some cases the creative choice of a product that was not mainstream. Examples of this would be the board game Monopoly, Southwest Airlines, or a computer dating service. Attractiveness and artistic skills in no way played a role in selection - pure analytical ability and presentation skill were what counted.

Student exemplars were chosen primarily for superior writing quality and depth. They anticipated "why?" questions from the reader and explained the rationale behind actions taken, not just cataloged facts. Numerical analysis was used whenever possible. A critical inclusion was the use of tables and graphs to enhance the text and simplify information processing by the reader.

Exemplars also lacked no elements asked for on the syllabus. Some rare examples were chosen for uniqueness of the product or service, to encourage choices other than the ubiquitous soft drinks or beer. Similarly, exemplars that were technically excellent but failed the spelling/punctuation/grammar test were included to affirm that the standards were adhered to despite otherwise high quality.

In the first test, three subsequent sections of the Marketing Management course were given multiple previous student project examples, along with the detailed outline of the project. Multiple student examples were necessary because even the best student work often misses key elements. However, taken as a group, the projects offered a complete view of the learning goals of the project.

\section{Information Quality}

To manipulate quality and provide a contrast to the student generated examples, the lead author completed an exemplar project using the outline and his own expectations of what would be possible for the students to accomplish. The exemplar generated went into great depth and provided a concrete expectation of what is expected of the student 
in terms of detail. Each of the topics shown in the course syllabus (see Appendix 1) was covered, and the level of detail expected in the paper was additionally designed to address the concerns raised by Gaidis and Andrews (1990).

By writing a paper specifically for the class, a number of pedagogical goals are accomplished:

1) The exemplar paper illustrates exactly what level of detail is expected, as well as the quality and style of writing. For example, students are only given eight English errors before losing a full letter grade. The paper was carefully inspected to ensure this standard was exceeded before being distributed to students.

2) The method of citing references in the body of the text as well as in the reference section is clearly shown. This eliminates questions later of what style is acceptable, or if any style is used at all. Previous experience has shown that students almost never cite their sources in the body of the paper, seriously degrading the value of the work if it were to be used in a corporate setting.

3) Demonstrating the requisite level of explanation for "why?" questions throughout the paper were demonstrated. Students often will supply a recommendation but never explain what its purpose is or who will benefit and how. The exemplar paper details the benefits received by customers, the company and other parties whenever a specific marketing action is recommended.

4) The paper shows how to deal with elements that are not applicable to a situation specifically addressed by indicating that such elements are not germane. This ensures that the professor knows the student realized the specific topic (for example, tariffs when dealing with Canada) was recognized as an issue but not one to be covered in this paper. Thus the professor knows that the student did not merely overlook an area that was called for in the syllabus.

Four subsequent and different sections of the same Marketing Management course were given the professor's exemplar paper, along with the detailed outline, in the second test. The two sets of results were then used for the purposes of analysis.

\section{Data Collection/Sample}

To avoid problems, including differences in teaching styles, expectations, course materials, a single professor's class was used to conduct the study. Nine sections of Marketing Management, the department capstone course, were utilized. Using the capstone course also ensured that the students had approximately the same background due to the stringent prerequisites. All students were within their last two semesters of graduating when taking these classes. Further, to avoid information leak from one class to another, no two manipulations we done during the same semester. In addition, increases in information were sequentially higher in consequent semestersthus the students could not use the exemplar project in outline-only manipulations because it had not previously been made available.

A total sample size of 182 students was obtained over nine sections of the course. The students' final grade on the project was used as the dependent measure of student performance. Dummy variables for each level of manipulation were used to test the hypotheses. In addition, the students' cumulative GPA was obtained and used as a surrogate measure of the students' ability and dedication. Including GPA as a covariate ensures that differential student ability is not a driving factor in the analysis. 


\section{RESULTS}

The results of the regression analysis are shown in Table 1. The model r-squared was 30.9\% with the model being significant.

\begin{tabular}{|c|c|c|c|}
\hline Variable & Coefficient & p-value & Results \\
\hline Constant & 86.1 & .000 & Projects grades averaged $86.1 \%$ \\
\hline $\begin{array}{l}\text { Previous } \\
\text { Student } \\
\text { Example } \\
\text { Projects }\end{array}$ & -7.85 & .000 & H1a: supported. Additional information retarded student performance. \\
\hline $\begin{array}{l}\text { Professor } \\
\text { Exemplar } \\
\text { Project } \\
\text { Available }\end{array}$ & -5.6 & .013 & $\begin{array}{l}\text { H1a: supported. Additional information retarded student performance. } \\
\text { H2: Supported. Students with Professor's exemplar project did better than those } \\
\text { with Previous Student projects ( } \mathrm{p}=.023 \text { - difference in coefficients) }\end{array}$ \\
\hline GPA & 13.75 & .000 & $\begin{array}{l}\text { Students with a } 1 \text { point higher GPA ( } 1 \text { grade level) performed about } 11 / 3^{\text {rd }} \text { grade } \\
\text { levels }(37.5 \%) \text { higher }\end{array}$ \\
\hline
\end{tabular}

As seen in Table 1, students who had access to previous student projects scored nearly $8 \%$ lower than outline-only students. Students who had access to the professor's exemplar project scored about a half grade lower $(5.6 \%)$ than outline-only access. When comparing information quality, the students with access to the professor's exemplar project performed 2.25 percent higher than those with the previous student projects (difference in coefficients p-value 0.23 ) - or about one-fourth of a grade higher.

Of marginal interest is that students with a one grade higher cumulative GPA performed slightly more than one grade higher on the project. This indicates that the grading on this project was in line with students previous grading in the students' other classes and can be suggested as an indicator of external validity of the grading scheme used.

\section{DISCUSSION}

Students perform best when under limited information circumstances. It is in this environment that they fully utilize their creative and thought processes. The lack of detailed samples to work from reflects the nature of most, perhaps all, marketing report challenges. In a real sense, students not bound by the limitations of previous efforts are more likely to find innovative solutions to the problem. Such creative thinking is a valuable asset to the firm. From the student's perspective, it is realistic training for work.

However, anecdotal evidence indicates that students are less comfortable when given limited information from which to work. Comments on student evaluations and classroom comments indicate that students perceive this as an environment of uncertainty which they tend to loathe. This could be a function of the several things, including the students' focus on grades, rather than learning; or perhaps concerns with workload. The professor thus faces a dilemma of whether to boost one's evaluations with extensive examples of projects previously done or provide more rigor and allow students to learn by doing and asking questions. Discussions with one's administration may help clarify which method benefits students more while at the same time protecting the professor's evaluations and potential merit raises.

Should a professor determine that students are in need of additional information, especially at the underclassman level, then the results indicate it is in the students' (and perhaps professor's) best interest is for the professor to complete the assignment as a template rather than using previous student assignments. 


\section{FUTURE RESEARCH}

This research relied on students who were near completion of their studies. Thus they had the proper preparation to be able to complete a research project from an outline, without additional information. This may or may not be true of students in lower division courses or beginning their studies in business (sophomore and new junior students). Thus we must temper the results with the caveat that the conclusions may be limited only to more advanced students.

It is reasonable to expect lower level student to have less polished business writing skills than seniors. Business writing has its own style, dissimilar to an English class essay or a biology lab report. One's skills will be improved more quickly by providing a sample of expected work. To really excel, however, students must learn to work with extraordinary situations, just as on calculus or chemistry tests you see problems similar to but less obvious than homework problems. Presumably seniors have a firm grasp of business writing and professor can challenge and extend that skill with fewer detailed instructions on writing assignments. It is suggested that continuing study be made of this topic using students at various stages in their marketing studies to determine if indeed skills are honed with time.

\section{REFERENCES}

1. Batra, Madan and Barbara Walvoord (1997), Effective Pedagogy for Student-Team Projects, Journal of Marketing Education, Summer, 26-42.

2. Florida Department of Education (2005), Proven Instructional Practices for High Quality Writing, Tallahassee, Fl: Florida Department of Education.

3. Gaidis, William and J. Craig Andrews (1990), Management of Experiential Learning Projects in Marketing Coursework, Journal of Marketing Education, Summer, 49-60.

4. Goretsky, M. Edward (1984), Class Projects as a Form of Instruction, Journal of Marketing Education, Fall, 33-37.

5. Henke, John, William Locander, John Mentzer and George Nastas III (1988), Teaching Techniques for the New Marketing Instructor: Bringing the Business World into the Classroom, Journal of Marketing Education, Spring, 1-10.

6. Johansson, Johny and Jan-Erik Vahlne, (1977), The Internationalization Process of the Firm-A Model of Knowledge Development and Increasing Foreign Market Commitments, Journal of International Business Studies, Spring/Summer, 23-32.

7. Karns, Gary (1993), Marketing Student Perceptions of Learning Activities: Structure, Preferences and Effectiveness, Journal of Marketing Education, Spring, 3-10.

8. McCorkle, Denny E., James Reardon, Joe F Alexander, Nathan D. Kling, Robert C. Harris and R. Vishwanathan, Iyer, (1999), Undergraduate Marketing Students, Group Projects, and Teamwork: The Good, the Bad, and the Ugly? Journal of Marketing Education, Vol. 21 No.2, August, 106-177

9. National Commission on Writing In America's Schools and Colleges, (2003), The neglected "R": the Need for a Writing Revolution, New York: College Board.

10. (2004) Writing: A Ticket to Work...Or a Ticket Out; A Survey of Business Leaders, New York: College Board.

11. Nelson, J., and Hayes, J. R., (1988), How the Writing Context Shapes the Students' Strategies for Writing from Sources, Tech. Report No. 16, Berkeley, CA: National Center for the Study of Writing and Literacy at the University of California, and Carnegie Mellon University.

12. Roach, Scott, Mark Johnston, and Joseph Hair Jr. (1993), An Exploratory Examination of Teaching Styles Currently Employed in Marketing Education: Developing a Typology and Its Implications for Marketing Students, Journal of Marketing Education, Fall, 32-38.

13. Schwegler, R. A. and Shamoon, L. K., (1982) The Aims and Process of the Research Paper, College English 44 (8) 817-824. 


\section{Appendix 1: Project Outline for Marketing Management}

Project: You will be divided into teams of up to 4 students or work alone. Each team will select a company that is publicly traded, choose ONE product from that firm, and undertake your role as a product management team. Your report will be an analysis of the marketing mix of your chosen product, with some additional areas covered. The written report itself will vary in length, but must contain the elements in the following outline. Make sure you read the papers on reserve to understand the format and coverage depth expected.

This is a marketing paper, so make sure you pay careful attention to marketing mix basics. For example, tell me what functions distributors will play in your plans, even if this information seems basic or obvious. Don't assume that I know anything - write down all your arguments and rationale for all actions. Also, I want your insights on things such as new product offerings and services — don't just repeat what the company is already doing. Plagiarism will result in a failing grade for the project.

The paper should be written according to the following format. Be sure to read the papers on reserve to see what errors to avoid.

1. Table of contents: This demands that you number of pages of your report as well.

2. Executive summary: (read sample provided to ensure you use the correct format)

3. Introduction: (read sample provided)

4. Environmental analysis: Identify three trends (1 in business, 1 social and 1 cultural or political or other) that will affect one or more of your products. What marketing actions will you take to deal with these new developments and why?

5. Consumer profile: Where possible, I expect census data to back up your segment sizes, whether they are regional or demographic. Describe in detail your product's segmentation strategy. Your analysis should include a detailed description of your consumer segment(s) and why you chose them. Check Marketing Atlas, or the Buying Power Issue for Sales and Marketing Management for help with current figures.

6. Competitive analysis/positioning map: Number, size and products of competitors' lines that are close competition to your own. This also means substitute goods or lower priced alternatives that do the job as well but may not look as nice. There must be a positioning map to illustrate where your product is perceived, as well as a table describing your product and competition's.

7. Product description: This must include information about the basic product, its class (impulse good, shopping good or specialty), stage in the life cycle, NAICS code, brand strategy, and packaging. If you believe that a different position should be adopted, explain why.

8. Product Line Management: Come up with a product line extension and explain its utility to both consumers and the company. This should be one YOU think up, not what the company is already doing.

9. Services: Devise a service component for your product and explain its value. Again, this is YOUR idea, not something already being done.

10. Distribution: Store choice, what the stores do to support your marketing plan, intensity level (intensive, selective, exclusive), basic strategies.

11. Pricing: Pricing strategy and defense of it. Discounts where applicable and why used. If you think an alternative approach is feasible, explain your reasoning and defend it.

12. Promotion: Analyze all aspects of your product's promotion strategy—sales promotion, personal selling, advertising and public relations. Explain how each element works and how well it works. Discuss the timing of the ad schedule and its intensity patterns. Analyze an ad for your product, explaining its audience, media choice and accuracy of placement, stopping power, attraction elements, message type and overall quality. What is the promotion goal? Explain the timing of promotions and their duration.

13. International: Pick a single country and tell me why you chose the country you will be entering. What entry strategy will you use? What changes in the marketing mix are necessary to succeed?

14. References: at least 3 non-company and 3 non-internet sources - not all from the Net and not all from the company itself. Proper citation format is essential. 
15. Appendix: This should contain your sample ads and other references and tables. A bibliography is required, as are citations in the body of the text. When you cite a source, immediately after the citation note its origin and author. EXAMPLE: The Arab states can be manipulated if cultivated carefully (Kissinger, 1974). See the professor's projects on reserve as an example.

$10 \%$ of your grade on any written assignment will be for spelling, grammar and punctuation. More than 8 errors will get a 0 for this portion of your grade. Any mistake from your editing hand-out or a typo that should have been picked up by spell check is an automatic 10\% reduction in grade. You will lose an additional 15 points if you misspell the name of your product or company. 